Jurnal Artikel

\title{
Optimasi Suhu dan Waktu Tahan Furnace Terhadap Kekerasan dan Mikro Struktur Deposit Lasan Elektroda Hardfacing
}

\author{
Basori $^{*}$, Ferry Budhi Susetyo ${ }^{2}$ \\ ${ }^{1}$ Teknik Mesin, Fakultas Teknik dan Sains Universitas Nasional \\ ${ }^{2}$ Teknik Mesin, Fakultas Teknik, Universitas Negeri Jakarta \\ 1 basori@civitas.unas.ac.id , ${ }^{2}$ fbudhi@unj.ac.id \\ *Corresponding author-Email : basori@civitas.unas.ac.id
}

Artkel Info - : Received : 16 Jul 2020; Revised : 20 Aug 2020; Accepted : 30 Aug 2020

Dalam penelitian ini dilakukan pengelasan HV 600 dengan empat kali (lapis). Proses pengelasan menggunakan arus 90 A polaritas DC+ pada spesimen baja karbon rendah. Kemudian dilakukan pemanasan pada tungku dengan variasi suhu $750^{\circ} \mathrm{C}, 800^{\circ} \mathrm{C}, 850^{\circ} \mathrm{C}$ dan $900^{\circ} \mathrm{C}$ dengan waktu tahan 10,20 dan 30 menit. Setelah ditahan dengan variasi waktu kemudian di celupkan dalam media pendingin air. Spesimen yang telah di perlakukan panas kemudian diuji keras untuk melihat kekerasan yang terbentuk serta mikro struktur dari spesimen tersebut. Hasil uji keras dan foto mikro bervariasi tergantung temperatur dan waktu tahan (holding time) yang digunakan.

Kata kunci: HV 600, SMAW, waktu tahan, variasi suhu

\section{Abstract}

In this study HV 600 welding was carried out four times (layers). The welding process uses 90 A polarities $D C+$ currents in low carbon steel specimens. Then heat the furnace with a temperature variation of 750 ${ }^{\circ} \mathrm{C}, 800{ }^{\circ} \mathrm{C}, 850{ }^{\circ} \mathrm{C}$ and $900{ }^{\circ} \mathrm{C}$ with a holding time of 10,20 and 30 minutes. After being held with variations of time then dip it in a water cooling media. Specimens that have been heat treated are then rigorously tested to see the hardness formed and the microstructure of the specimen. Hard test results and the microstructure vary depending on the temperature and holding time used.

Keywords: HV 600, SMAW, holding time, furnace temperature

\section{LATAR BELAKANG}

Sifat mekanik dari suatu logam sangat beragam jenisnya seperti sifat mekanik kekerasan, sifat mekanik ketangguhan, dan sifat mekanik tarik. Dari semua sifat yang telah disebutkan, sifat mekanik kekerasan merupakan yang utama diharapkan ketika proses hardfacing dilakukan (Syaripuddin, Rohma, \& Susetyo, 2019).

Saat ini proses hardfacing dengan metode SMAW banyak dilakukan, karena biayanya rendah serta mudah diaplikasikan. Proses hardfacing ini umumnya diterapkan pada baja karbon rendah untuk meningkatkan sifat kekerasan dari material tersebut, karena material baja karbon rendah sulit dilakukan heat treatment karena kadar karbon yang relatif rendah (Sopiyan, Susetyo, \& Syamsuir, 2018).

Ketika melakukan proses heat treatment dimana hasil yang diharapkan adalah sifat kekerasan maka suhu dan waktu tahan merupakan parameter yang penting dipertimbangkan agar didapatkan hasil yang optimal (Purwanto, 2011). Temperatur austenisasi baja beragam 
sehingga diperlukan suhu yang tepat ketika melakukan heat treatment sesuai dengan komposisi baja (Karmin, 2009). Baja S45 C dilakukan pemanasan $850{ }^{\circ} \mathrm{C}$ dengan menggunakan variasi waktu holding time 10, 20 dan 30 menit menghasilkan kekerasan tertinggi pada holding time 30 menit (Widodo \& Huda, 2016).

Selain suhu dan waktu tahan media pendingin juga berperan terhadap hasil kekerasan yang terbentuk. Dari empat media pendingin yaitu air, air garam, minyak kelapa dan oli, media pendingin air menghasilkan kekerasan paling tinggi dengan holding time 20 menit (Ayu V \& Sumiati, 2020).

Berdasarkan paparan di atas maka akan dilakukan penelitian mengenai optimasi waktu tahan dan suhu dalam tungku (furnace) untuk menghasilkan kekerasan yang maksimal.

\section{METODOLOGI}

Proses penelitian ini daiawali dengan pengelasan HV $600 \quad(0,6 \% \quad$ C) pada material baja karbon rendah $(0,2 \% \quad \mathrm{C})$ menggunakan las jenis SMAW. Proses pengelasan dilakukan dengan empat lapis menggunakan arus 90 A polaritas DC+. Setelah selesai proses pengelasan kemudian spesimen dilakukan pemanasan pada tungku dengan variasi suhu $750^{\circ} \mathrm{C}$, $800^{\circ} \mathrm{C}, 850^{\circ} \mathrm{C}$ dan $900^{\circ} \mathrm{C}$. Selain dari variasi suhu yang telah disebutkan, dilakukan juga variasi waktu tahan 10, 20 dan 30 menit. Setelah ditahan dengan variasi waktu kemudian di celupkan dalam media pendingin. Adapun media pendingin yang digunakan pada proses quenching adalah air. Spesimen yang telah di quenching kemudian diuji keras vickers dengan beban 5kgf untuk melihat kekerasan yang terbentuk serta mikro struktur dengan perbesaran 50x dari spesimen tersebut.

\section{HASIL DAN PEMBAHASAN \\ 3.1 Hasil Uji Kekerasan}

Sebagai berikut merupakan hasil uji kekerasan suhu $750{ }^{\circ} \mathrm{C}$ dengan variasi waktu tahan 10, 20 dan 30 menit

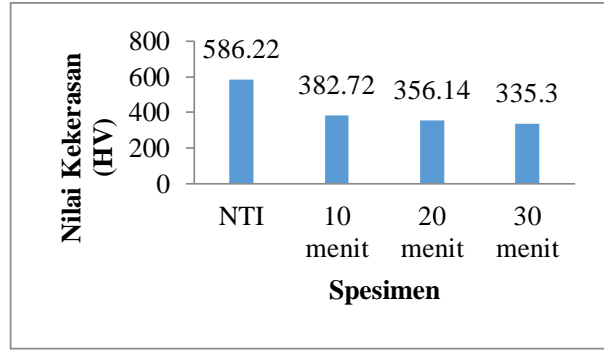

Gambar 3.1 Hasil Uji kekerasan Suhu $750^{\circ} \mathrm{C}$ Variasi Waktu Tahan

Hasil uji keras pada spesimen $750{ }^{\circ} \mathrm{C}$ menunjukkan semakin lama waktu tahan maka akan semakin menurun kekerasannya. Hal ini terjadi karena proses pemanasan belum mencapai temperatur austenit (Murtiono, 2012). Sehingga tidak terjadi transformasi austenit menjadi martensit (Karmin, 2009). Sebagai berikut merupakan hasil uji kekerasan suhu $800^{\circ} \mathrm{C}$ dengan variasi waktu tahan 10, 20 dan 30 menit.

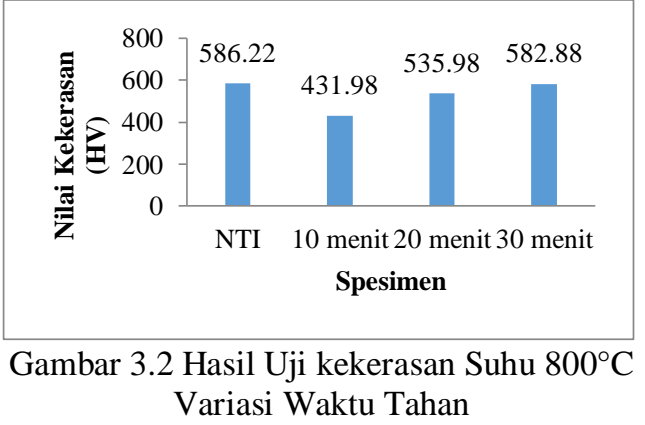

Pada spesimen $800{ }^{\circ} \mathrm{C}$ menunjukkan semakin lama waktu tahan maka akan semakin naik kekerasannya. Hal ini sesuai dengan penelitian yang telah dilakukan pada baja amutit dengan variasi waktu penahanan 10, 20, 30 dan 40 dimana kekerasan semakin naik dengan bertambahnya waktu tahan (Effendi, 2009). Sebagai berikut merupakan hasil uji kekerasan suhu $850{ }^{\circ} \mathrm{C}$ dengan variasi waktu tahan 10, 20 dan 30 menit.

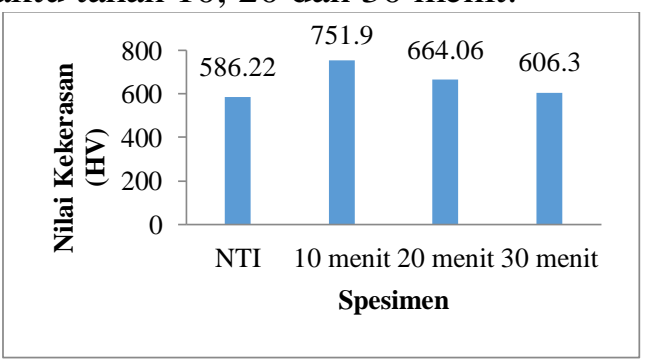


Gambar 3.3 Hasil Uji kekerasan Suhu $850^{\circ} \mathrm{C}$ Variasi Waktu Tahan

Pada spesimen $850 \quad{ }^{\circ} \mathrm{C}$ menunjukkan semakin lama waktu tahan maka akan semakin turun kekerasannya. Hal ini sesuai dengan penelitian yang dilakukan pada hasil lasan HV 600 yang dilakukan pengelasan sebanyak dua lapis kemudian dipanaskan hingga suhu $1000{ }^{\circ} \mathrm{C}$ dan dilakukan variasi holding time 10, 20 dan 3 menit menghasilkan semakin lama waktu tahan maka akan semakin turun nilai kekerasan dari material baja tersebut (Susetyo, Basori, \& Maryanto, 2020). Hal ini disebabkan karena ukuran butir akan semakin besar ketika semakin lama dipanaskan dalam tungku (Utama, Wahab, \& Robbi, 2016). Sebagai berikut merupakan hasil uji kekerasan suhu $900^{\circ} \mathrm{C}$ dengan variasi waktu tahan 10, 20 dan 30 menit

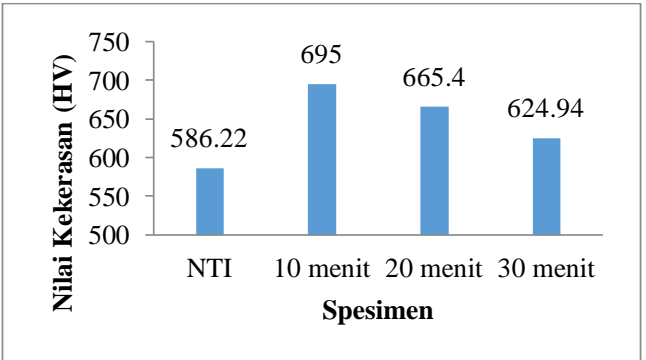

Gambar 3.4 Hasil Uji kekerasan Suhu $900^{\circ} \mathrm{C}$ Variasi Waktu Tahan

Pada spesimen $900{ }^{\circ} \mathrm{C}$ menunjukkan semakin lama waktu tahan maka akan semakin turun kekerasannya. Hal ini sesuai dengan penelitian yang dilakukan pada baja ASSAB 760 dengan variasi suhu $800{ }^{\circ} \mathrm{C}$, $840{ }^{\circ} \mathrm{C}, 880^{\circ} \mathrm{C}$ dan variasi holding time 15 , 25 dan 35 menit, menghasilkan semakin lama waktu tahan maka akan semakin turun nilai kekerasan dari material baja tersebut (Utama et al., 2016). Berikut merupakan perbandingan hasil uji kekerasan variasi suhu dan variasi waktu tahan.

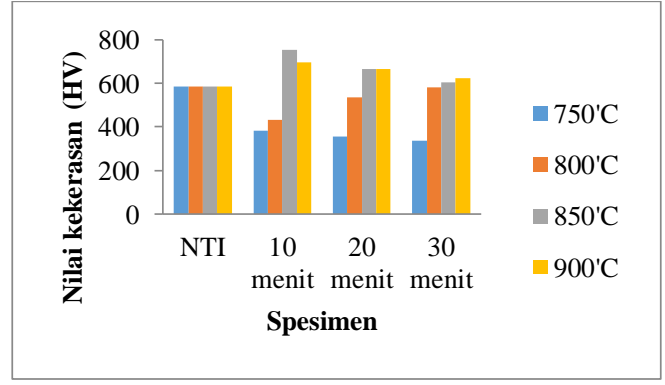

Gambar 3.5 Perbandingan Hasil Uji kekerasan Variasi Suhu dan Waktu Tahan

Dari gambar di atas dapat terlihat kekerasan tertinggi didapatkan pada suhu $850{ }^{\circ} \mathrm{C}$ dengan waktu tahan selama 10 menit. Sedangkan kekerasan terendah terlihat pada spesimen $750{ }^{\circ} \mathrm{C}$ dengan waktu tahan 30 menit. Sehingga suhu $850^{\circ} \mathrm{C}$ dengan waktu tahan 10 menit merupakan parameter yang tepat digunakan untuk menghasilkan kekerasan yang maksimal.

\subsection{Hasil Foto Mikro}

Sebagai berikut merupakan hasil foto mikro.

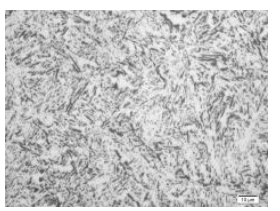

(a)

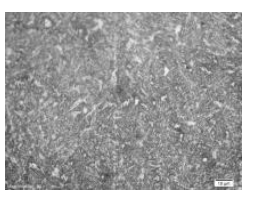

(b)

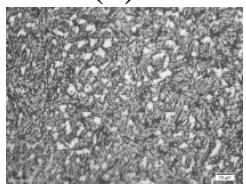

(e)

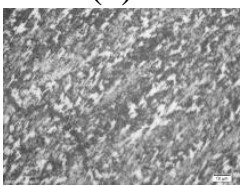

(h)

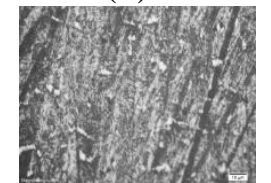

(k)

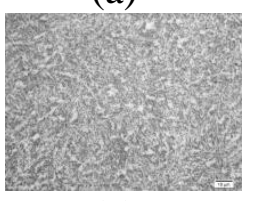

(c)

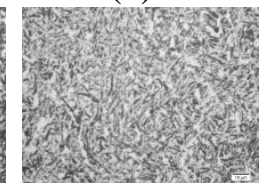

(f)

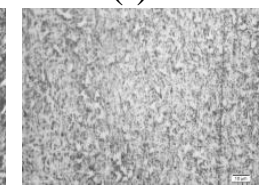

(i)

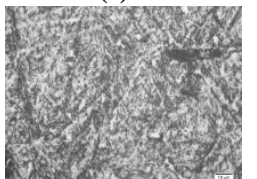

(1)

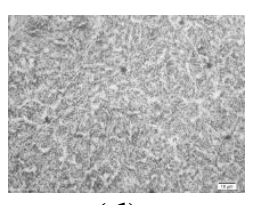

(d)

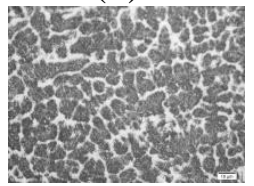

(g)

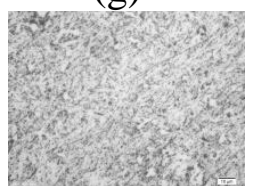

(j)

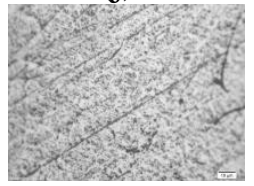

(m)
Gambar 3.6 Perbandingan Hasil Foto Mikro Variasi Suhu dan Waktu Tahan (a) NTI, (b) 10750 , (c) 20-750, (d) 30-750, (e) 10-800, (f) 20-800, (g) 30-800, (h) 10-850, (i) 20-850, (j) 30-850, (k) 10-900, (l) 20-900, (m) 30-900

Berdasarkan gambar di atas dominasi ferrit, pearlite dan martensit terlihat tersebar pada hasil foto mikro (Utama et al., 2016). Pada spesimen dengan nilai kekerasan tertinggi yaitu spesimen pada 
suhu $850{ }^{\circ} \mathrm{C}$ dengan waktu tahan selama 10 menit terlihat sebaran martensit, sedangkan spesimen dengan kekerasan terendah (NTI) terlihat sebaran ferrit dan pearlit.

\section{KESIMPULAN}

Kesimpulan yang dapat ditarik dari penelitian yang telah dilakukan adalah hasil uji keras pada spesimen $750{ }^{\circ} \mathrm{C}$ menunjukkan semakin lama waktu tahan maka akan semakin menurun kekerasannya. Pada spesimen $800{ }^{\circ} \mathrm{C}$ menunjukkan semakin lama waktu tahan maka akan semakin naik kekerasannya. Pada spesimen $850{ }^{\circ} \mathrm{C}$ menunjukkan semakin lama waktu tahan maka akan semakin turun kekerasannya. Pada spesimen $900{ }^{\circ} \mathrm{C}$ menunjukkan semakin lama waktu tahan maka akan semakin turun kekerasannya. Sehingga suhu $850^{\circ} \mathrm{C}$ dengan waktu tahan 10 menit merupakan parameter yang tepat digunakan untuk menghasilkan kekerasan yang maksimal.

\section{DAFTAR PUSTAKA}

Ayu V, F. D., \& Sumiati, S. (2020). Desain Eksperimen Pengaruh Variasi Media Pendingin Terhadap Kekerasan Dan Kekuatan Tarik Bahan St 41 Pada Proses Heat Treatment. Jurnal Manajemen Industri Dan Teknologi, 1(3), 104115.

Effendi, S. (2009). Pengaruh Perbedaan Waktu Penahanan Suhu Stabil Terhadap Kekerasan Logam. Jurnal Austenit, 1(1), 39-43.

Karmin. (2009). Pengendalian proses pengerasan baja dengan metoda quenching. Jurnal Austenit, 1(2), 1725.
Murtiono, A. (2012). Pengaruh Quenching dan Tempering Terhadap Kekerasan dan Kekuatan Tarik serta Struktur Mikro Baja Karbon Sedang untuk Mata Pisau Pemanen Sawit. EDinamis, II(2), 57-70.

Purwanto, H. (2011). Analisa Quenching Pada Baja Karbon Rendah Dengan Media Solar. Momentum, 7(1), 3640.

Sopiyan, Susetyo, F. B., \& Syamsuir. (2018). Pengaruh Arus Terhadap Kenyamanan Welder, Cacat Las Dan Kekerasan Hasil Hardfacing Baja Karbon. Jurnal Kajian Teknik Mesin, 3(2), 57-107.

Susetyo, F. B., Basori, I., \& Maryanto, D. (2020). Pengaruh Direct Dan InDirect Quenching Dengan Media Air Terhadap Kekerasan Hasil Hardfacing Baja Karbon. Jurnal Asiimetrik, 2(2), 125-131.

Syaripuddin, Rohma, K., \& Susetyo, F. B. (2019). Pengaruh Penambahan Unsur Nikel/ Karbon Pada Deposit Las Elektroda E6013 Terhadap Sifat Mekanik. Jurnal Konversi Energi Dan Manufaktur, 6(1), 22-29.

Syaripuddin, S., Susetyo, F. B., Aribowo, A. H., \& Nofendri, Y. (2019). Kekuatan Tarik Multilapis Deposit Las Beberapa Produk Komersial Elektroda AWS A. 51 E6013. MECHANICAL, 10(1), 15-18.

Utama, A. R. S., Wahab, A., \& Robbi, N. (2016). Pengaruh temperatur dan holding time dengan pendingin yamacoolant terhadap baja ASSAB $760,6(1)$.

Widodo, E., \& Huda, M. (2016). Optimasi Holding Time Untuk Mendapatkan Kekerasan Baja S 45 C. Rekayasa Energi Manufaktur, 1(1), 1-6. 